\title{
Validity and clinical utilization of the Chinese version of the Gotland Male Depression Scale at a men's health polyclinic
}

This article was published in the following Dove Press journal:

Neuropsychiatric Disease and Treatment

10 September 2014

Number of times this article has been viewed

\author{
Chun-Lin $\mathrm{Chu}^{\mathrm{I}-3}$ \\ Yu Chen ${ }^{1,3,4}$ \\ Kun-Hao Jiang ${ }^{1,3,5}$ \\ Jiun-Liang Chen ${ }^{1,3,5}$ \\ Chin-Pang Lee ${ }^{1-3}$ \\ Yeuk-Lun Chau ${ }^{1,2}$ \\ Ching-Yen Chen ${ }^{1-3}$ \\ 'Men's Health Center, ${ }^{2}$ Department \\ of Psychiatry, Chang Gung Memorial \\ Hospital at Linkou, ${ }^{3}$ School \\ of Medicine, Chang Gung University, \\ ${ }^{4}$ Department of Urology, ${ }^{5}$ Department \\ of Traditional Chinese Medicine, \\ Chang Gung Memorial Hospital \\ at Linkou, Taoyuan, Taiwan
}

Introduction: Symptoms of depression in males, such as aggression and irritability, are different from those in females. However, there are no adequate scales for detecting possible diagnoses in the Chinese population. The aim of this study was to assess whether the Chinese version of the Gotland Male Depression Scale (CV-GMDS) could identify male depression as effectively as the English version.

Materials and methods: A total of 231 male outpatients were sampled from a men's health polyclinic. We used questionnaires to evaluate the characteristics and mood status of participants, including the CV-GMDS, the Chinese version of the Beck Depressive Inventory II (CVBDI-II), and the Chinese version of the Aging Males' Symptoms (CV-AMS) scale. Cronbach's $\alpha$-coefficient and Levene's test were used to investigate internal consistency and homogeneity, respectively. External validity was evaluated using Spearman's correlation coefficient. A factor analysis was conducted to evaluate the conceptual structure of the CV-GMDS, and a regression analysis was used to determine the relationship of the CV-AMS scale with the CV-GMDS and CV-BDI-II

Results: The mean age of the 231 participants was 46.1 years (standard deviation 11.0). Of the participants, $36.8 \%(\mathrm{n}=85)$ were found to have depression according to the CV-GMDS and $34.6 \%(n=80)$ according to the CV-BDI-II. The internal consistency of the CV-GMDS was demonstrated by a Cronbach's $\alpha$ of 0.933 , and the test of homogeneity revealed a $P$-value of 0.762 . The external validity for the CV-GDMS and CV-BDI-II was demonstrated by an intercorrelation of 0.835 . The third and fourth items of the GMDS differed from the others, and the CV-GMDS showed a better relationship $\left(R^{2}=0.616\right)$ with the CV-AMS scale than the CV-BDI-II did.

Conclusion: The CV-GMDS is a satisfactory and suitable psychometric questionnaire for detecting depression among a Chinese-speaking middle-aged or older male population. The results of this study could be used as a basis for investigating specific male depression and aging symptoms.

Keywords: male depression, validation, utilization, Gotland Male Depression Scale, Aging Males' Symptoms scale

\section{Introduction}

Depression in males is a severe problem that many men neglect or refuse to face. Depression can lead to consequences, such as substance abuse, sexual dysfunction, domestic violence, pathological gambling, and even suicide. ${ }^{1}$ In general, not enough attention is given to this problem in clinical practice, because we have limited information about it. Sex is becoming an increasingly important issue in understanding physical and emotional health, and depression in particular. ${ }^{2}$ Past studies have suggested that depression in men is reported and diagnosed less often. ${ }^{3}$ Epidemiological
Correspondence: Ching-Yen Chen Department of Psychiatry, Chang Gung Memorial Hospital at Linkou, 5 Fu-Shin Street, Guei-Shan, Taoyuan 333, Taiwan Tel +8863328 I200 ext 2439 Fax +88633280267 Email 56phantom@gmail.com submit your manuscript | www.dovepress.com

Dovepress

http://dx.doi.org/1 0.2147/NDT.S67617
Neuropsychiatric Disease and Treatment 20।4:10 1707-I7I4 
statistics show that females suffer from depressive illness twice as often as males. Different coping skills for managing stress between females and males may explain this result. However, if different symptoms occur in male versus female depression, there is another possible explanation. ${ }^{4}$ Aggression and problems with anger play an important role in depression. Furthermore, these symptoms are related to lower impulse control and are more prevalent in males than in females. ${ }^{5}$ If the aggressive component in male depression is controlled for, there are no sex differences in depression. ${ }^{6}$ Some symptoms of male depression may be easily ignored using current criteria or scales. Researchers also believe that traditional self-report scales for evaluating depression, like the Beck Depression Inventory (BDI), may be sex-biased, and thus fail to include symptoms that may be important in male depression. ${ }^{7}$ Therefore, there is a need for a new assessment tool that includes those atypical depressive symptoms recognized in men.

Many clinicians and investigators have examined the adequacy of detection of depression in males. After a high suicide rate among Swedish men in the 1980s was found by Rutz, ${ }^{8}$ the number of male suicides on the Gotland island was almost unaffected by the educational program for improving the ability of general practitioners to diagnose and treat depression. A focus on the unique aspects of depression in males occurred. Concerns were raised whether suicide is related to an unknown category of depression, and "male depressive syndrome" was proposed based on this research in 2001. ${ }^{9}$ This syndrome is characterized by low stress tolerance, acting-out behavior, low impulse control, substance abuse, a hereditary loading of depressive illness, alcoholism, and suicide. The Gotland Male Depression Scale (GMDS), designed by Zierau et $\mathrm{l}^{10}$ was developed to better understand depression in men and further prevent suicide according to this syndrome. The GMDS is a 13 -item self-administered questionnaire including dimensions of depression and distress (eg, irritability, aggression, and alcohol use). Currently, the GMDS is a popular screening tool for clinical studies investigating mood changes in men.

In Taiwan, the specific symptoms mentioned earlier regarding male depression are usually missed, even during interviews by mental health professionals. Chinese version of scales, such as the BDI-II or Montgomery-Åsberg Depression Rating Scale, ${ }^{11-13}$ are still used clinically for detecting depression in males generally. The concept of male depression is still being established. The underlying processes of male depression still require further study, as they thus far have lacked sufficient evidence. No adequate scale can be used for evaluating possible expressions of male depression among the Chinese population. Fortunately, the GMDS has been used extensively for male depression and suicide in some Western countries for years. To compare results with different cultures, the GMDS was translated into Chinese, and an attempt was made to validate the use of this Chinese version for Taiwanese males, based on a sample from a men's health polyclinic.

The goal of this study was to assess whether the Chinese version of the GMDS (CV-GMDS) could measure male depression as effectively as the English version and be utilized for aging symptoms.

\section{Materials and methods Subjects}

A total of 231 male outpatients were sampled from a men's health polyclinic from July 2008 to March 2009. The polyclinic was located in Chang Gung Memorial Hospital, the largest medical center in Taiwan, and consisted of three different specialties: urology, psychiatry, and Chinese medicine. When men visited this clinic initially, regardless of whether they intended to visit one or all specialists, they were asked to complete several questionnaires about mood, sleep, sexuality, and physical status. Included in these questionnaires were the GMDS, the BDI-II, and the Aging Male's Symptoms (AMS) scale. ${ }^{14,15}$ All participants were men who could communicate verbally, were not exhibiting psychosis, and had no cognitive dysfunction. Participants took about 15-20 minutes to complete the questionnaires, and were supervised by a medical assistant.

\section{Demographic data}

Basic demographic data included age, education, marital status, and employment status.

\section{Chinese version of the Gotland Male Depression Scale}

The GMDS is composed of 13 self-report items divided into two subscales (Figure S1). The distress subscale contains items $1,2,5,8,9,10$, and 12, and the depression subscale contains items 3, 4, 6, 7, 11, and 13. Each question is rated on a 4 -point Likert scale from 0 to 3 , and thus the total score can range from 0 to 39 . Total scores of different ranges correspond to the following descriptions: 0-12 indicates no depression, 13-26 indicates probable depression for which an antidepressant should be considered, and 27-39 indicates definite depression for which an antidepressant should be prescribed. With regard to the translation, we received 
permission from Rutz ${ }^{10}$ to translate the GMDS into Chinese. The standard method of forward translation, back-translation and check, and test-retest was completed for the translation of the English version of the GMDS into Chinese. The process was continued until the Chinese version appeared interchangeable with the English version. An experienced psychiatrist (CYC) and two independent translators, both native Chinese speakers who were fluent in English, conducted the forward translation of the GMDS into Chinese. Two professional translators, both native English speakers who were fluent in Chinese, executed the back-translation of the first intermediate translation into Chinese. Finally, the Chinese version of the GMDS was completed (Figure S2).

\section{Chinese version of the Beck Depressive Inventory II}

The BDI-II is a 21-item self-administered questionnaire developed in 1996 for assessing the degree of depression. ${ }^{11}$ It consists of two main dimensions: depressive and physical symptoms. Each item of the BDI-II is rated on a 4-point Likert scale (ranging from 0 to 3 ), and the total score ranges from 0 to 63 points. In the original (American) version, the descriptions for total scores are as follows: 0-13 shows no depression, 14-19 shows mild depression, 20-28 shows moderate depression, and 29-63 shows severe depression. However, a different result was found in the Chinese version. ${ }^{12}$ The best cutoff point for indicating possible depression was equal to or higher than 17 for Taiwanese on the CV-BDI-II.

\section{Chinese version of the Aging Males' Symptoms scale}

The AMS scale is a 17-item self-report scale for assessing the severity of aging symptoms in men. ${ }^{14}$ This scale includes three domains covering psychological, somatovegetative, and sexual symptoms. A 5-point Likert scale, ranging from 1 to 5, was used to rate each item of the AMS scale. Total scores range from 17 to 85 . Higher total scores indicate more severe aging symptoms. Total scores of 17-26 indicate no aging symptoms, 27-36 mild aging symptoms, 37-49 moderate aging symptoms, and $\geq 50$ severe aging symptoms. The AMS scale was translated into a valid and reliable Chinese version in $2007 .^{15}$

\section{Statistical analysis}

All statistical data were analyzed using SPSS version 17 for Windows. We analyzed the consistency, homogeneity, and validity between questionnaires, including the two subscales of the CV-GMDS. To examine internal consistency, we used
Cronbach's coefficient $(\alpha)$. Coefficients between 0.70 and 0.90 were considered acceptable, and those above 0.90 were clinically acceptable. Levene's test was used to evaluate equality of variances; results of $P>0.05$ were defined as acceptable.

We used Spearman's correlation coefficient to investigate external validity and explain interscale correlations. The results of coefficients $>0.70$ were distinct from those $<0.70$, in that more than $50 \%$ of the variance of the variables was explained by the association in the former.

Guttman split-half reliability was used to measure equivalence for the CV-GMDS. A coefficient of 0.80 or higher shows adequate reliability and 0.90 or higher shows good reliability in a common rule of thumb. To examine the conceptual structure of the CV-GMDS, we applied a factoranalytic procedure with a two-factor structure. Finally, we used multiple regression analysis to compare the strength of the relationships between the CV-AMS scale, the CV-GMDS, and the CV-BDI-II.

\section{Results}

\section{Demographic and clinical characteristics}

The mean age of the 231 participants who completed the questionnaires was 46.1 (standard deviation 11.0) years. Of these participants, $62(26.8 \%)$ were less than 40 years old, $81(35.1 \%)$ were $40-49$ years, $63(27.3 \%)$ were $50-59$ years, and $25(10.8 \%)$ were older than 60 years. With respect to education, 51 (22.1\%) participants had attended junior high school or less, and $180(77.9 \%)$ participants had attended senior high school or more. Furthermore, 184 (79.6\%) males were single, including unmarried, divorced, and widowed, while 47 (20.4\%) males were married. In addition, there were $52(22.5 \%)$ unemployed participants, including retirees, and $179(77.5 \%)$ participants were employed (Table 1).

Table I Description of the participants: percentage of characteristics

\begin{tabular}{lll}
\hline & $\mathbf{n = 2 3} \mathbf{1}$ & $\%$ \\
\hline Age (years) & & \\
$<40$ & 62 & 26.8 \\
$40-49$ & 81 & 35.1 \\
$50-59$ & 63 & 27.3 \\
$\geq 60$ & 25 & 10.8 \\
Education & & \\
Junior high school and below & 51 & 22.1 \\
Senior high school and above & 180 & 77.9 \\
Marital status & & \\
Single (unmarried, divorced, widowed) & 184 & 79.6 \\
Married/cohabitating & 47 & 20.4 \\
Employment & & \\
Unemployed & 52 & 22.5 \\
Employed & 179 & 77.5 \\
\hline
\end{tabular}




\section{Internal validity}

The level of internal consistency for the two questionnaires is shown in Table 2. Both scales had clinically acceptable Cronbach's $\alpha$-coefficients (0.933). The distress subscale of the CV-GMDS was also clinically acceptable (0.909), whereas the depression subscale was acceptable, but not at a clinical level (0.844). We found that scales with more items tended to have higher coefficients.

The homogeneity of the two questionnaires is also shown in Table 2. The $P$-values of all scales, including two subscales, were clearly acceptable, and the highest homogeneity was for the CV-BDI-II (0.983). Regarding the homogeneity of the CV-GMDS, the total score had a higher value (0.762) than the distress and depression dimensions, at 0.728 and 0.694 , respectively. Levene's test might have been affected by the number of items.

\section{External validity}

The interscale correlations for the CV-GMDS and CV-BDI-II are displayed in Table 3. Clinically acceptable correlations were shown for both scales and for two subscales, because all the coefficients were higher than 0.70. The CV-GMDS total scores and CV-BDI-II had the strongest correlations (0.835); the two subscales of the CV-GMDS had somewhat lower correlations (the distress dimension was 0.803 and the depression dimension was 0.79 ) with the CV-BDI-II. The two subscales of the CV-GMDS were correlated at 0.821 .

\section{Reliability}

The equivalence for the CV-GMDS by maximum split-half reliability revealed good reliability $\left(\lambda_{4}=0.95\right)$.

\section{Factor structure}

The results of the factor analysis for the CV-GMDS are shown in Table 4. All items were positively related to male

Table 2 Internal validity (internal consistency and homogeneity) of the CV-GMDS and CV-BDI-II

\begin{tabular}{|c|c|c|}
\hline & $\begin{array}{l}\text { Cronbach's } \\
\text { coefficient } \\
(\alpha)\end{array}$ & $\begin{array}{l}\text { Levene's test of } \\
\text { homogeneity } \\
(P)\end{array}$ \\
\hline CV-GMDS (total) (I 3 items) & 0.933 & 0.762 \\
\hline $\begin{array}{l}\text { Gotland distress dimension } \\
\text { (7 items) }\end{array}$ & 0.909 & 0.728 \\
\hline $\begin{array}{l}\text { Gotland depression } \\
\text { dimension (6 items) }\end{array}$ & 0.844 & 0.694 \\
\hline CV-BDI-II (2I items) & 0.933 & 0.983 \\
\hline
\end{tabular}

Abbreviations: CV-GMDS, Chinese version of the Gotland Male Depression Scale; CV-BDI-II, Chinese version of the Beck Depression Inventory II.
Table 3 External validity (intercorrelations) between the CVGMDS and CV-BDI-II

\begin{tabular}{llll}
\hline & $\begin{array}{l}\text { Gotland } \\
\text { (distress) }\end{array}$ & $\begin{array}{l}\text { Gotland } \\
\text { (depression) }\end{array}$ & $\begin{array}{l}\text { CV- } \\
\text { BDI-II }\end{array}$ \\
\hline CV-GMDS (total) & 0.963 & 0.945 & 0.835 \\
$\begin{array}{l}\text { Gotland distress } \\
\text { dimension }\end{array}$ & & 0.821 & 0.803 \\
$\begin{array}{l}\text { Gotland depression } \\
\text { dimension }\end{array}$ & & & 0.79 \\
\hline
\end{tabular}

Abbreviations: CV-GMDS, Chinese version of the Gotland Male Depression Scale; CV-BDI-II, Chinese version of the Beck Depression Inventory II.

depression. The third item, "feeling of being burned out and empty", and the fourth item, "constant, inexplicable tiredness", had loadings higher than 0.5 on the second factor, which differed from other items.

\section{Relationship with the CV-AMS scale}

In this study, 204 (88.3\%) participants met the mild, moderate, or severe aging symptoms according to the CV-AMS scale. In contrast, 85 (36.8\%) of males presented possible or evident depression on the CV-GMDS, and 80 (34.6\%) males had mild, moderate, or severe depression as measured by the CV-BDI-II. Furthermore, we found that the CV-GMDS $\left(R^{2}=0.616\right)$ correlated more with the CV-AMS scale than did the CV-BDI-II $\left(R^{2}=0.574\right)$ (Table 5).

\section{Discussion}

This study evaluated whether the CV-GMDS is a useful screening tool for identifying hidden male depression in Chinese-speaking population. The internal consistency of the total scores and distress and depression subscale scores on the CV-GMDS were 0.93, 0.91, and $0.84(\mathrm{n}=213)$, respectively. The initial study of the GMDS reported the internal consistency of the English version to be $0.86,0.78$, and $0.75(n=87)$, respectively. ${ }^{10}$ Therefore, the CV-GMDS demonstrated slightly better internal consistency, which may have been a result of having more participants. Therefore, the CV-GMDS is satisfactory and suitable in terms of consistency.

In the present study, the CV-GMDS was compared with another popular tool, the CV-BDI-II, to examine the validity of the CV-GMDS in measuring emotional symptoms. The total score of the CV-GMDS, as well as both subscales, correlated positively with the CV-BDI-II $(0.84,0.80$, and 0.79 , respectively). Similar data were reported in a Western study with a similar number and source of participants. ${ }^{16}$ Consequently, the CV-GMDS has good construct validity.

We used a two-step translation procedure to ensure consistent content validity of the questionnaires. Because 
Table 4 Factor structure of the Chinese version of the Gotland Male Depression Scale

\begin{tabular}{|c|c|c|}
\hline \multirow[t]{2}{*}{ Content } & \multicolumn{2}{|c|}{ Factor } \\
\hline & $\mathbf{I}$ & 2 \\
\hline I. Lower stress threshold/more stressed out than usual & $0.8 I^{*}$ & 0.00 \\
\hline 2. More aggressive, outward-reacting, difficulties keeping self-control & $0.77^{*}$ & 0.00 \\
\hline 3. Feeling of being burned out and empty & $0.72 *$ & $0.52^{*}$ \\
\hline 4. Constant, inexplicable tiredness & $0.70^{*}$ & $0.58^{*}$ \\
\hline 5. More irritable, restless, and frustrated & $0.82 *$ & 0.11 \\
\hline 6. Difficulty making ordinary everyday decisions & $0.8 I^{*}$ & 0.00 \\
\hline 7. Sleep problems: sleeping too much/too little/restlessly, difficulty falling asleep/waking up early & $0.62^{*}$ & 0.28 \\
\hline 8. In the morning especially, having a feeling of disquiet/anxiety/uneasiness & $0.76 *$ & -0.14 \\
\hline $\begin{array}{l}\text { 9. Overconsumption of alcohol and pills in order to achieve a calming and relaxing effect. Being hyperactive } \\
\text { or blowing off steam by working hard and restlessly, jogging or other exercises, under- or overeating }\end{array}$ & $0.62 *$ & -0.14 \\
\hline $\begin{array}{l}\text { 10. Do you feel your behavior has altered in such a way that neither you yourself nor others can recognize } \\
\text { you, and that you are difficult to deal with? }\end{array}$ & $0.83^{*}$ & -0.25 \\
\hline $\begin{array}{l}\text { II. Have you felt or have others perceived you as being gloomy, negative, or characterized by a state of } \\
\text { hopelessness in which everything looks bleak? }\end{array}$ & $0.84 *$ & -0.21 \\
\hline $\begin{array}{l}\text { 12. Have you or others noticed that you have a greater tendency to self-pity, to be complaining, or to seem } \\
\text { "pathetic"? }\end{array}$ & $0.84^{*}$ & -0.31 \\
\hline $\begin{array}{l}\text { 13. In your biological family, is there any tendency toward abuse, depression/dejection, suicide attempts, or } \\
\text { proneness to behavior involving danger? }\end{array}$ & $0.50 *$ & -0.35 \\
\hline
\end{tabular}

Note: *Factor loading $>0.50$.

the CV-GMDS included items about depressive expressions and feelings of distress, a masked variable might explain the close relationship between similar items. Factor analysis was conducted to examine biases underlying the scale, although this process was not checked in the original study. Interestingly, we found the third and fourth items loaded on the depressive subscale, a finding that is so far specific to the Chinese population.

Aging is an issue that has been discussed in recent years, especially among males. Insomnia has been suggested as a fair predictor of aging symptoms across all age-groups of men. ${ }^{17}$ Andropause and anxiety/depression can also be distinguished in aging men by sexual dysfunction. ${ }^{18}$ However, there is still a lack of research on the expression of depression in aging men. Therefore, we examined which scale is better at identifying "hidden" depression in aging males between the CV-GMDS and the CV-BDI-II. A better relationship was found between the CV-AMS scale and the CV-GMDS than between the CV-AMS scale and the CV-BDI-II. Given that the distress subscale is specific to the GMDS, we speculated

Table 5 Relationship with depression and the CV-AMS scale for the CV-GMDS and CV-BDI-II

\begin{tabular}{lll}
\hline & CV-GMDS & CV-BDI-II \\
\hline Depression & $36.80 \%$ & $34.60 \%$ \\
CV-AMS scale $\left(R^{2}\right)$ & 0.616 & 0.574 \\
\hline
\end{tabular}

Abbreviations: CV-GMDS, Chinese version of the Gotland Male Depression Scale; CV-BDI-II, Chinese version of the Beck Depression Inventory II; CV-AMS, Chinese version of the Aging Males' Symptoms. that maybe distress is an important factor in men with aging males' depression.

It is of vital importance that we have a better understanding for atypical expression of depression in males. One study in Taiwan indicated that participants of younger ages and from relatively homogeneous social backgrounds may not be useful in explaining sex differences in self-reported depression. ${ }^{19}$ In some reports, the GMDS indicated no sex differences in a group of suicidal depressed inpatients, which may be explained by the notion that suicidal females have a male-type depression profile. ${ }^{20-22}$ One study also stressed that the GMDS could be a useful tool in screening and identifying those affective disorder patients who are at higher risk of suicidal behavior, regardless of sex. ${ }^{23}$ Maybe the GMDS not only focuses on males but also exerts its specificity in the general population with suicidal ideas. Nevertheless, male depressive and distress symptoms are usually mixed and hard to separate; an additional minor factor should be emphasized for male distress symptoms, especially with respect to irritability. Therefore, male distress symptoms need to be considered carefully when diagnosing depression in men. ${ }^{24}$ The GMDS includes the symptoms and signs related to the presentation of male depression that typically get less attention. Our study indicates that use of the CV-GMDS could be explored in outpatient services and community samples. We need not only to educate ourselves about male symptoms of depression, but also to include male-specific assessment tools in clinical practice. 


\section{Limitations}

This study had some limitations. First, a control group of healthy participants for the validation of the CV-GMDS was lacking. In a general process, a healthy group for comparison with the study group is important. Therefore, the finding in this study maybe defines a preliminary result for validity. Second, test-retest reliability was not presented. This examination is widely used to determine the stability of a scale at a separate time, usually 2-4 weeks. It should be included in a complete study design. Third, a clear diagnosis for depression is also limited. The procedure of definite diagnosis for mood status will increase the accuracy of utilization in clinical practice. The Mini-International Neuropsychiatric Interview or the Diagnostic and Statistical Manual of Mental Disorders could be considered for further studies.

\section{Conclusion}

Overall, the CV-GMDS is a useful psychometric assessment among the Chinese-speaking male population. This selfadministered screening tool is sensitive and similar to the BDI-II at identifying masked depression in men. The CVGMDS has better utility for investigating specific depression in aging males than the BDI-II. Currently, there is a lack of research on the clinical applications of the GMDS in Asian countries. In addition, the validity demonstrated in this study can be used as the basis for comparing the results of the CVGMDS with those of the GMDS in other languages.

\section{Disclosure}

The authors report no conflicts of interest in this work.

\section{References}

1. Kilmartin C. Depression in men: communication, diagnosis and therapy. J Mens Health Gend. 2005;2(1):95-99.

2. Bird CE, Ricker PP. Gender matters: an integrated model for understanding men's and women's health. Soc Sci Med. 1999;48(6):745-755.

3. Kuehner C. Gender differences in unipolar depression: an update of epidemiological findings and possible explanations. Acta Psychiatr Scand. 2003;108(3):163-174.

4. Khan AA, Gardner CO, Prescott CA, Kendler KS. Gender differences in the symptoms of major depression in opposite-sex dizygotic twin pairs. Am J Psychiatry. 2002;159(8):1427-1429.

5. Winkler D, Pjrek E, Kasper S. Anger attacks in depression - evidence for a male depressive syndrome. Psychother Psychosom. 2005;74(5): 303-307.

6. Rutz W, von Knorring L, Pihlgren H, Rihmer Z, Wålinder J. Prevention of male suicides: lessons from Gotland study. Lancet. 1995; 345(8948):524.
7. Solokangas RK, Vaahtera K, Pacriev S, Sohlman B, Lehtinen V. Gender differences in depressive symptoms. An artifact caused by measurement instruments? J Affect Disord. 2002;68(2-3):215-220.

8. Rutz W. Improvement of care for people suffering from depression: the need for comprehensive education. Int Clin Psychopharmacol. 1999;14 (Suppl 3):S27-S33.

9. Walinder J, Rutz W. Male depression and suicide. Int Clin Psychopharmacol. 2001;16(Supp1 2):S21-S24.

10. Zierau F, Bille A, Rutz W, Bech P. The Gotland Male Depression Scale: a validity study in patients with alcohol use disorder. Nord J Psychiatry. 2002;56(4):265-271.

11. Beck AT, Steer RA, Brown GK. Manual for the Beck Depression Inventory-II. San Antonio: Psychological Corporation; 1996.

12. Lu ML, Che HH, Chang SW, Shen WT. [Reliability and validation of Chinese version of the Beck Depression Inventory-II]. Formos J Med. 2002;16:301-310. Chinese.

13. Montgomery SA, Asberg M. A new depression scale designed to be sensitive to change. Br J Psychiatry. 1979;134:382-389.

14. Heinemann LAJ, Zimmermann T, Vermeulen A, Thiel C, Hummel W. A new 'aging males' symptoms (AMS)' rating scale. Aging Male. 1999;2(2):105-114.

15. Chen CY, Wang WS, Liu CY, Lee SH. Reliability and validity of a Chinese version of the Aging Males' Symptoms scale. Psychol Rep. 2007;101(1):27-38.

16. Strömberg R, Backlund LG, Löfvander M. A comparison between the Beck's Depression Inventory and the Gotland Male Depression Scale in detecting depression among men visiting a drop-in clinic in primary care. Nord J Psychiatry. 2010;64(4):258-264.

17. Chiu YW, Chu CL, Chen Y, et al. Complaint of insomnia as a predictor of aging symptoms in males at a men's health clinic. Aging Male. 2012; 15(1):7-13.

18. Chen CY, Lee CP, Chen Y, Jiang JR, Chu CL, Chen CL. The correlation between emotional distress and aging males' symptoms at a psychiatric outpatient clinic: sexual dysfunction as a distinguishing characteristic between andropause and anxiety/depression in aging men. Clin Interv Aging. 2013;8:635-640.

19. Yao YC, Chen CY. Gender differences in depressive symptoms and their relation to personality traits. Taiwan J Psychiatry. 2009; 23(4):284-295.

20. Möller-Leimkühler AM, Bottlender R, Strauss A, Rutz W. Is there evidence for a male depressive syndrome in inpatients with major depression? J Affect Disord. 2004;80(1):87-93.

21. Innamorati M, Pompili M, Gonda X, et al. Psychometric properties of the Gotland Scale for Depression in Italian psychiatric inpatients and its utility in the prediction of suicide risk. J Affect Disord. 2011; 132(1-2):99-103.

22. Rihmer Z, Rutz W, Rihmer A, Gonda X, Webb R, Kapur N. Do suicidal females have "male-type" depression? Eur Psychiatry. 2009;24 (Suppl 1):S183.

23. Pompili M, Innamorati M, Rihmer Z, et al. Cyclothymic-depressiveanxious temperament pattern is related to suicide risk in 346 patients with major mood disorders. J Affect Disord. 2012;136(3):405-411.

24. Möller Leimkühler AM, Heller J, Paulus NC. Subjective well-being and "male depression" in male adolescents. J Affect Disord. 2007; 98(1-2):65-72. 


\section{Supplementary material}

\section{The Gotland Male Depression Scale}

\begin{tabular}{lll}
\hline Wolfgang Rutz, M.D., Ph.D. & Zoltán Rihmer, M.D., Ph.D. & Arne Dalteg, Ph.D. \\
Psychiatrist, Visby & Psychiatrist, Budapest & Psychologist, Visby
\end{tabular}

English version: Per Bech, Lis Raabæk Olsen, Vibeke Nørholm, Psykiatrisk Forskningsenhed, Hillerød

During the past month, have you or others noticed that your behavior has changed, and if so, in which way?

\begin{tabular}{|c|c|c|c|c|}
\hline & $\begin{array}{l}\text { Not } \\
\text { at all }\end{array}$ & $\begin{array}{l}\text { To some } \\
\text { extent }\end{array}$ & $\begin{array}{l}\text { Very } \\
\text { true }\end{array}$ & $\begin{array}{l}\text { Extremely } \\
\text { so }\end{array}$ \\
\hline I. Lower stress threshold/more stressed out than usual & $\square$ & $\square$ & $\square$ & $\square$ \\
\hline 2. More aggressive, outward-reacting, difficulties keeping self-control & $\square$ & $\square$ & $\square$ & $\square$ \\
\hline 3. Feeling of being burned out and empty & $\square$ & $\square$ & $\square$ & $\square$ \\
\hline 4. Constant, inexplicable tiredness & $\square$ & $\square$ & $\square$ & $\square$ \\
\hline 5. More irritable, restless and frustrated & $\square$ & $\square$ & $\square$ & $\square$ \\
\hline 6. Difficulty making ordinary everyday decisions & $\square$ & $\square$ & $\square$ & $\square$ \\
\hline 7. Sleep problems: sleeping too much/too little/restlessly, difficulty falling asleep/waking up early & $\square$ & $\square$ & $\square$ & $\square$ \\
\hline 8. In the morning especially, having a feeling of disquiet/anxiety/uneasiness & $\square$ & $\square$ & $\square$ & $\square$ \\
\hline $\begin{array}{l}\text { 9. Overconsumption of alcohol and pills in order to achieve a calming and relaxing effect. Being } \\
\text { hyperactive or blowing off steam by working hard and restlessly, jogging or other exercises, } \\
\text { under- or over-eating }\end{array}$ & $\square$ & $\square$ & $\square$ & $\square$ \\
\hline $\begin{array}{l}\text { 10. Do you feel your behavior has altered in such a way that neither you yourself nor others can } \\
\text { recognize you, and that you are difficult to deal with? }\end{array}$ & $\square$ & $\square$ & $\square$ & $\square$ \\
\hline $\begin{array}{l}\text { 11. Have you felt or have others perceived you as being gloomy, negative, or characterized by a } \\
\text { state of hopelessness in which everything looks bleak? }\end{array}$ & $\square$ & $\square$ & $\square$ & $\square$ \\
\hline $\begin{array}{l}\text { 12. Have you or others noticed that you have a greater tendency to self-pity, to be complaining } \\
\text { or to seem "pathetic"? }\end{array}$ & $\square$ & $\square$ & $\square$ & $\square$ \\
\hline $\begin{array}{l}\text { 13. In your biological family, is there any tendency towards abuse, depression/dejection, suicide } \\
\text { attempts or proneness to behaviour involving danger? }\end{array}$ & $\square$ & $\square$ & $\square$ & $\square$ \\
\hline \multicolumn{5}{|l|}{ 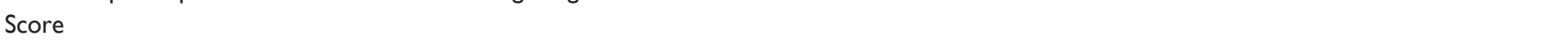 } \\
\hline \multicolumn{5}{|l|}{$0-13:$ No signs of depression. } \\
\hline \multicolumn{5}{|l|}{ 13-26: Depression possible. Specific therapy, including psychopharmacological, possibly indicated. } \\
\hline 26-39: Clear signs of depression. Specific therapy, including psychopharmacological, clearly indicate & & & & \\
\hline
\end{tabular}

Figure SI The English version of the Gotland Male Depression Scale. 


\section{(Gotland男性憂巍量表)}

在過去幾個月裡, 你或你的行為是否有所改變? 如果有, 是在那些方面?

完全 有些 非常 完全

没有 同意 同意 同意

(0) (1) (2) (3)

I. 壓力承受點降低/比往常更緊繃

2. 具有較侵略性的、激動的反應, 較難控制自己的情緒

3. 感到精疲力盡, 被掏空的感覺

4. 持續的或莫名的倦急感

5. 易怒、焦躁不安和有挫敗感

6. 對於一般日常的事物, 難以作抉擇

7. 睡眠障礙: 嗜睡/睡太少/睡得不安稻或難以入眠/早起

8. 早上時特別會感到不安、焦慮或擔心

9. 依賴酒精或藥物來達到鎮定和放鬆的效果。藉由不停地

工作、慢跑或是其它運動、大吃大掲或是少吃來讓自己 感到充滿精力或是紓解壓力

10. 你是否發覺到自己的行為改變讓自己或其他人都覺得

如同判若兩人, 而你却不知如何處理這様的情形?

II. 你自己或是他人覺得你有陰沈、負面的特質或是對任何事情都了無生趣?

12. 你自己或是他人察覺到你較易於有自哀自憐、抱怨、或引人憐惜的傾向?

13. 在你的家族中, 是否有人有虐待、憂鬱/沮喪或企圖自殺的傾向亦或是傾

向於作出危險的行為?

總分：

計分

0-12: 没有憂鬱的徵兆

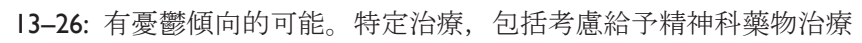

27-39: 有明顯憂鬱傾向。特定治療, 包括給予精神科藥物治療

Figure S2 The Chinese version of the Gotland Male Depression Scale.

\section{Publish your work in this journal}

Neuropsychiatric Disease and Treatment is an international, peerreviewed journal of clinical therapeutics and pharmacology focusing on concise rapid reporting of clinical or pre-clinical studies on a range of neuropsychiatric and neurological disorders. This journal is indexed on PubMed Central, the 'PsycINFO' database and CAS, and is the official journal of The International Neuropsychiatric Association (INA). The manuscript management system is completely online and includes a very quick and fair peer-review system, which is all easy to use. Visit http://www.dovepress.com/testimonials.php to read real quotes from published authors. 